\title{
Congenital and Developmental Abnormalities of the Hand and Wrist
}

\author{
Filip M. Vanhoenacker, MD, PhD ${ }^{1,2,3}$ \\ Nathalie Boutry, MD, PhD ${ }^{5}$ \\ 1 Department of Radiology, Antwerp University Hospital/University of \\ Antwerp, Edegem, Belgium \\ ${ }^{2}$ Department of Radiology, AZ Sint-Maarten, Mechelen, Belgium \\ ${ }^{3}$ Department of Radiology, Ghent University Hospital/University of \\ Ghent, Ghent, Belgium \\ ${ }^{4}$ Department of Pediatric Radiology and Medical Imaging, Hôpital \\ Universitaire Des Enfants Reine Fabiola (HUDERF), Université Libre \\ de Bruxelles, Bruxelles, Belgium \\ ${ }^{5}$ Department of Pediatric Radiology, Jeanne de Flandre Hospital, CHU \\ Lille, France
}

Address for correspondence Filip M. Vanhoenacker, MD, PhD, Department of Radiology, University Hospital of Antwerp UZA, Wilrijkstraat 10, 2650 Edegem, Belgium (e-mail: filip.vanhoenacker@telenet.be).

Semin Musculoskelet Radiol 2021;25:260-271.

\begin{abstract}
Identification of congenital skeletal abnormalities is complex because of the large variety of individual syndromes and dysplasias that are often difficult to remember. Although a correct diagnosis relies on a combination of clinical, radiologic, and genetic tests, imaging plays an important role in selecting those patients who should be referred for further genetic counseling and expensive genetic tests. In addition to information derived from radiologic analysis of other skeletal elements, radiographs of

Keywords

- Hand

- Wrist

- Radiography

- Congenital

- Developmental the hand and wrist may provide particular useful information. In the first part of this article, we provide a guide for a systematic radiologic analysis of the hand and wrist bones that may help characterize congenital and developmental diseases. Special attention is given to the use of correct terminology. In the second part, we discuss typical examples of congenital and developmental diseases involving the hand and wrist, with an emphasis on skeletal dysplasias.
\end{abstract}

A thorough analysis of the bones of the hand and wrist may be an important part of imaging analysis of congenital skeletal malformations and dysplasias. Radiologists are often overwhelmed when they are requested to interpret radiographs in the context of hereditary musculoskeletal disorders because of the complexity of imaging findings and the large spectrum of rare individual congenital disorders. Moreover, radiologic findings are often nonspecific and/or subtle.

In the first part of this article, we provide a guide for the systematic analysis of radiologic features that may help characterize congenital and developmental diseases of the hand and wrist, with special attention to the use of the correct terminology. ${ }^{1}$ In the second part, we discuss typical examples of congenital and developmental diseases involving the hand and wrist, with which the radiologist should be familiar.

\section{Radiologic Semiology and Terminology}

Radiologic analysis is based on the evaluation of cardinal and additional criteria, summarized in - Table 1 and further illustrated here.

\section{Cardinal Criteria}

\section{Overall Morphology}

The overall morphology of the hand is the first parameter to examine. In achondroplasia a characteristic trident morphology of the hand is seen (-Fig. 1). Storage diseases such as mucopolysaccharidoses causing dysostosis multiplex congenita may result in a very plump hand resembling a spade (hence the name "spade hand") (-Fig. 2 ).
Issue Theme Hand and Wrist Imaging: Guest Editors, Iwona Sudoł-Szopińska, MD, PhD and Maryam Shahabpour, MD (c) 2021. Thieme. All rights reserved. Thieme Medical Publishers, Inc., 333 Seventh Avenue, 18th Floor, New York, NY 10001, USA
DOI https://doi.org/ 10.1055/s-0040-1722613. ISSN 1089-7860. 
Table 1 Summary of cardinal and additional criteria for analysis of congenital disorders involving the hand and wrist

\begin{tabular}{|l|l|}
\hline Cardinal criteria & Additional criteria \\
\hline Overall morphology & Abnormal bone age \\
\hline Length of bones & $\begin{array}{l}\text { Abnormalities in mineralization, } \\
\text { either sclerosis or demineralization }\end{array}$ \\
\hline Shape of bones & Joint configuration \\
\hline Number of bones & Calcifications \\
\hline & $\begin{array}{l}\text { Associated bone and soft } \\
\text { tissue tumors }\end{array}$ \\
\hline & Soft tissue findings \\
\hline
\end{tabular}

\section{Length of Bones}

The next step is to evaluate the length of the individual bones of the hand, looking for shortening of various phalanges, thumb, and metacarpals.

"Brachydactyly: is the general term for short digits that can be subdivided in eight different subtypes, originally described by Bell (A1-4, B, C, D, and E), ${ }^{2}$ although it is not always possible to classify every individual case of brachydactyly with this classification (-Fig. $\mathbf{3}$ ).

"Brachymetacarpalia" refers to a more specific term used to designated short metacarpals, whereas brachytelephalangy and brachymesophalangy are used to indicate shortening of the distal and middle phalanges, respectively. ${ }^{3}$

Shortening of metacarpal 4 (and 5), causing a positive metacarpal sign (Archibald's sign) is seen in a variety of disorders including Turner's syndrome, pseudohypoparathyroidism, and pseudo-pseudohypoparathyroidism. This sign is positive when a line drawn along the heads of the fourth and fifth metacarpals intersects the head of the third metacarpal (-Fig. 4). Shortening of the fourth metacarpal may occur as a normal variant as well. ${ }^{4,5}$

In many conditions, overlapping signs of brachymetacarpalia and brachydactyly are seen. ${ }^{3}$

Arachnodactyly are elongated and slender tubular bones of the hand and may be seen in inherited connective tissue disorders including Marfan's syndrome (-Fig. 5), Beals syndrome, homocystinuria, and Ehlers-Danlos syndrome. ${ }^{3}$

\section{Number of Bones}

Abnormalities in the number of bones are referred to as oligodactyly ( - Fig. 6), in case of lack of fingers, and polydactyly, if there are too many fingers (-Fig. 7).

Based on the location of the absent digits, the terminology "radial ray" (-Fig. 6), "ulnar ray" syndrome, central ray (mesoaxial) deficiency, or terminal transverse defects is used. ${ }^{7}$

Ectrodactyly, also known as split, cleft, or lobster hand, is a descriptive term previously used to designate a central ray deficiency The name "ectrodactyly" is derived from the Greek ektroma ("abortion") and daktylos ("finger") reflecting the deficiency or absence of one or more central digits of the hand (-Fig. S1). It may also involve the foot.

Amniotic band syndrome is a condition believed to occur as a result of constriction bands in utero. The presence of

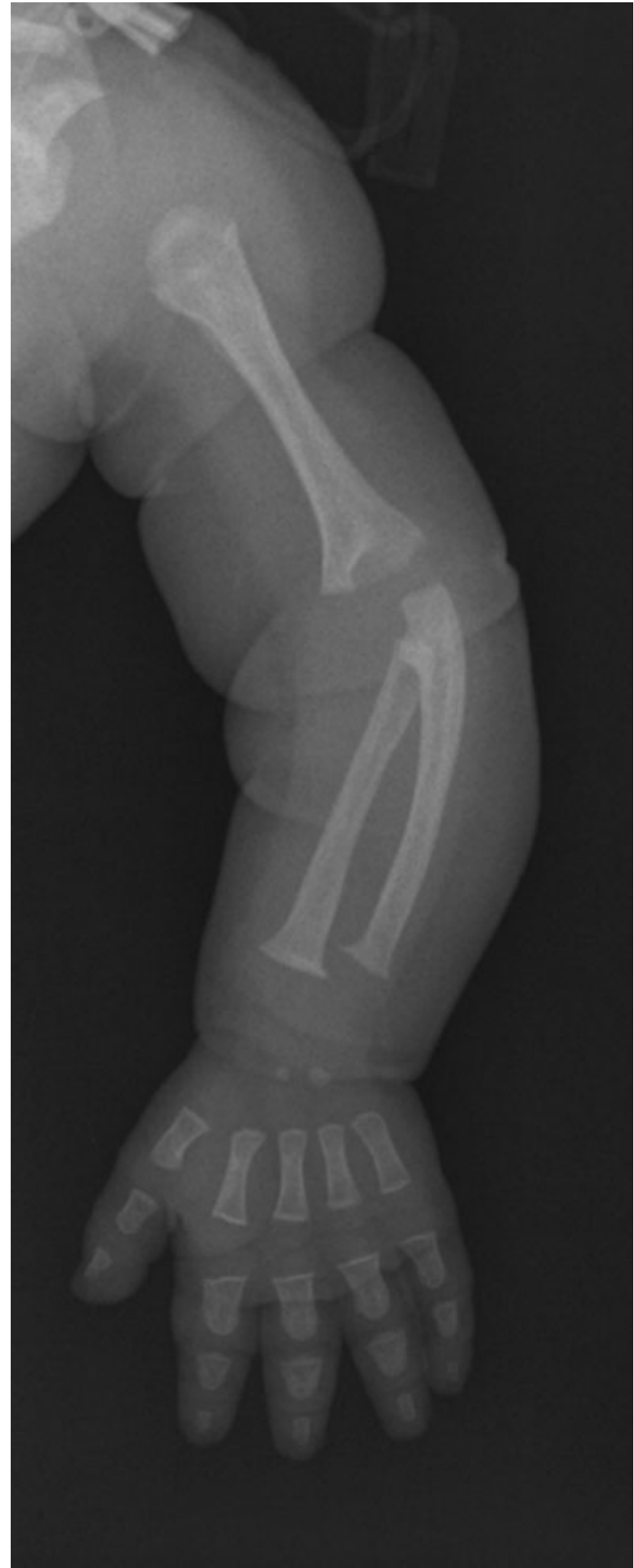

Fig. 1 Achondroplasia. Plain radiograph of the left upper limb. Note shortening of the long bones and bullet-shaped appearance of the phalanges that is most pronounced at the middle phalanges. Note also a trident morphology of the hand with splaying of the three middle fingers that are of equal length.

ringlike depressions in the skin, which are often indirectly visible on radiographs, is the clue to differentiate amniotic band syndrome from transverse defects. 


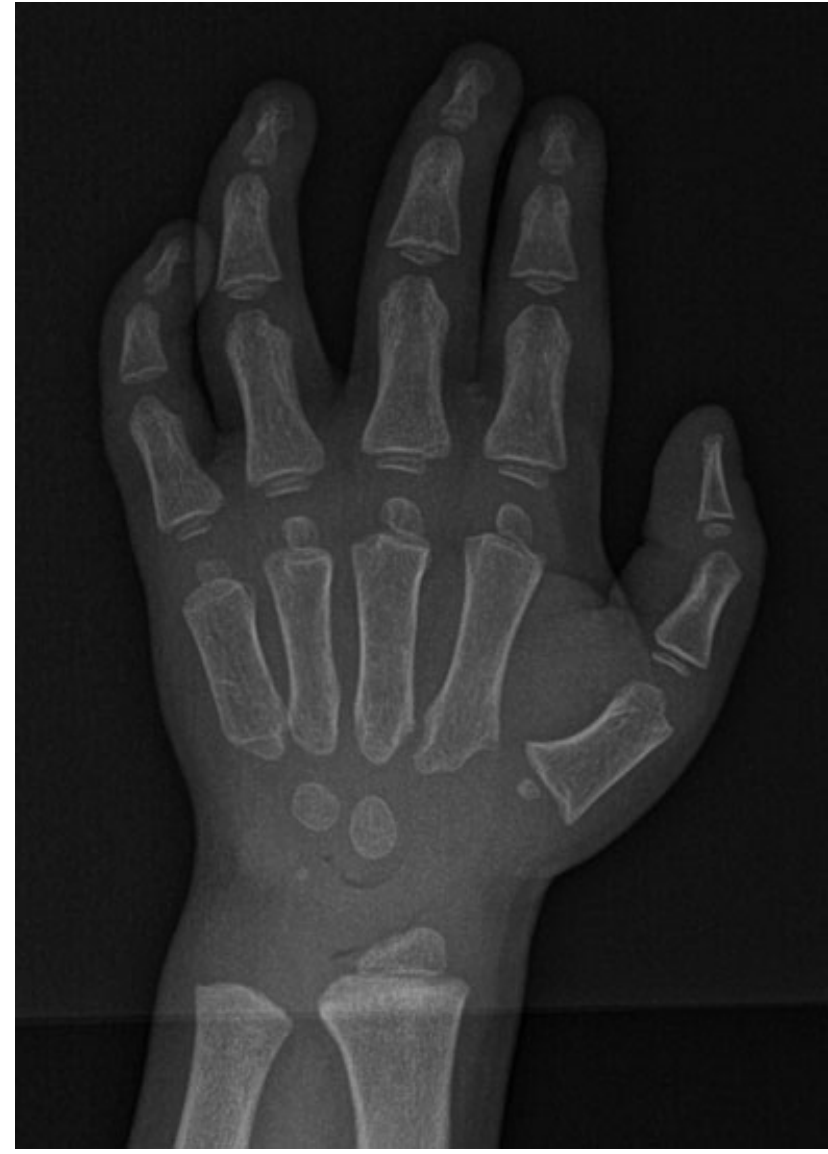

Fig. 2 Mucopolysaccharidoses. Radiograph of the right hand showing a "spade hand" in Hurler's syndrome. Note also flexion deformity of the fingers at the level of the interphalangeal joints, most pronounced at the distal interphalangeal joint of the fifth finger. There is a bullet-shaped deformity of the proximal and middle phalanges and pointing of the proximal ends of metacarpals 1 to 4 .

Complete absence of the hand due to a transverse deficiency is known as acheiria. ${ }^{8}$

A supernumerary finger can be either preaxial (on the radial side), postaxial (on the ulnar side) ( - Fig. 7 ), mesoaxial
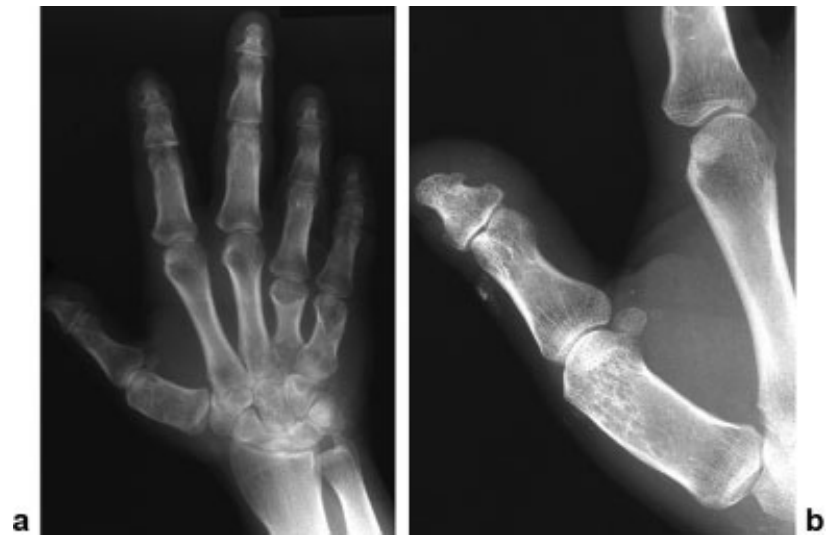

Fig. 4 Pseudohypoparathyroidism. Radiographs of (a) the right hand and (b) thumb showing shortening of metacarpal 1 and particularly of metacarpals 4 and 5 (positive metacarpal sign) and soft tissue calcifications at the dorsal aspect of the proximal phalanx of the thumb.

(middle finger), or complex (comprising combined abnormalities). ${ }^{1,8}$ In case of mesoaxial polydactyly, there is often a Y-shaped duplication of the third metacarpal. ${ }^{8}$ Polydactyly can occur in association with short ribs, in a number of polydactyly-short rib syndromes (- Fig. 7). ${ }^{8}$

Ulnar dimelia is very rare and characterized by duplication of the ulna, absence of the radius, radial carpal bones and fingers, and postaxial polydactyly with midline symmetry, hence the name "mirror hand" 8,9 (-Fig. 8).

A triphalangeal thumb is characterized by an elongated thumb comprising three rather than the usual two phalanges and can present as a sporadic occurrence or in association with other inherited hand and foot abnormalities ${ }^{3}$ ( - Fig. S2).

\section{Fusion of Bones}

Fusion occurring between two or more (adjacent) fingers is called syndactyly ( - Fig.9), whereas symphalangism ( - Fig. 10) refers to fusion between two phalanges within the same ray. Because symphalangism represents a failure in segmentation, the term "fusion" is a misnomer. Syndactyly can be

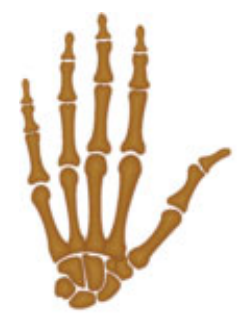

Normal

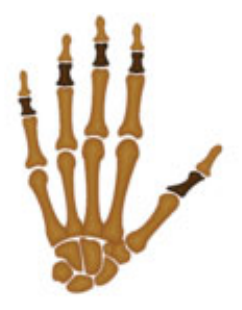

Type A1

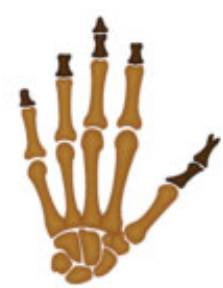

Type B

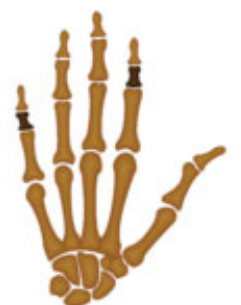

Type A2

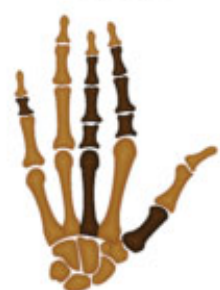

Type C

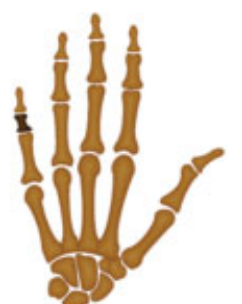

Type A3

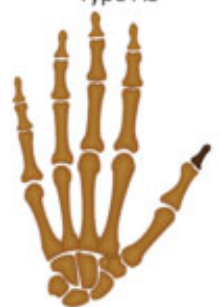

Type D

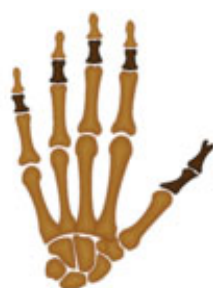

Type A4

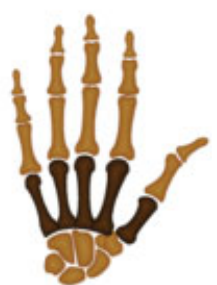

Type E

Fig. 3 Bell's classification of brachydactyly. 


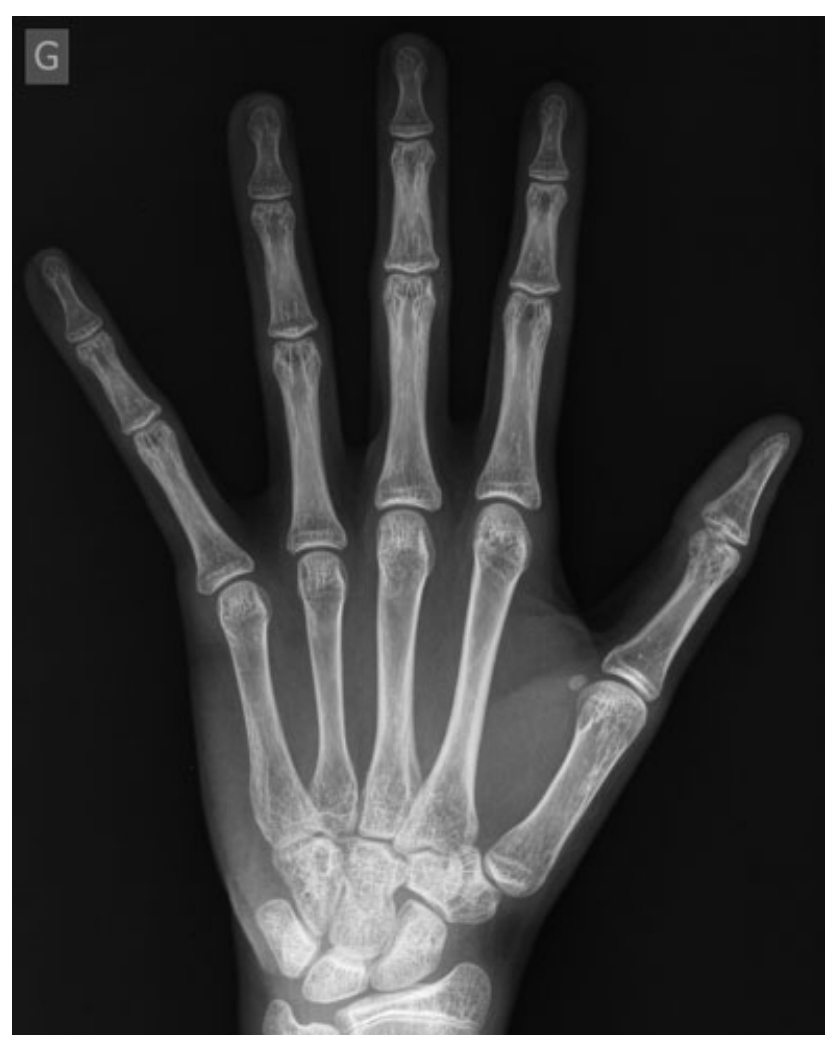

Fig. 5 Arachnodactyly in Marfan's disease. Radiographs of the left hand show long and slender metacarpals and phalanges.

membranous, bony (-Fig. 9), or combined and located either preaxial (on the radial side), postaxial (on the ulnar side), mesoaxial (middle finger), or associated with polydactyly (synpolydactyly). ${ }^{8}$

Symphalangism can be subdivided based on the location as proximal (at the proximal interphalangeal joint), distal (at the distal interphalangeal joint), or variable (distally and proximally located within the same patient) (-Fig. 10). Symphalangism may be completely bony or fibrous.

Fusion between carpal (or tarsal) bones is a frequent finding (-Fig. 11 and -Fig. S3) that is usually isolated but can be associated with several syndromes. ${ }^{10,11}$ Similar to symphalangism, the abnormality represents a failure in segmentation, and therefore the term "fusion" or "coalition" is a misnomer. ${ }^{8}$ Isolated coalitions usually involve two adjacent carpal bones within the same row, whereas multiple coalitions extending across the carpal rows may be associated with congenital syndromes. $^{8,12}$

\section{Shape of Bones}

Changes in morphology may involve the phalanges, the carpal, metacarpals, and distal radius and ulna. The phalanges may have a bullet shape in a variety of skeletal dysplasias including achondroplasia and dysostosis multiplex congenita $^{13}$ (- Figs. 1 and $\mathbf{2}$ ).

"Acro-osteolysis" is the term used for distal phalangeal resorption. This is usually due to acquired causes such as frostbite, scleroderma, psoriasis, and Raynaud's phenomenon, but congenital disorders such as pyknodystosis ${ }^{14}$ (-Fig. 12) or progeria (-Fig. 13) or other progeroid syn-

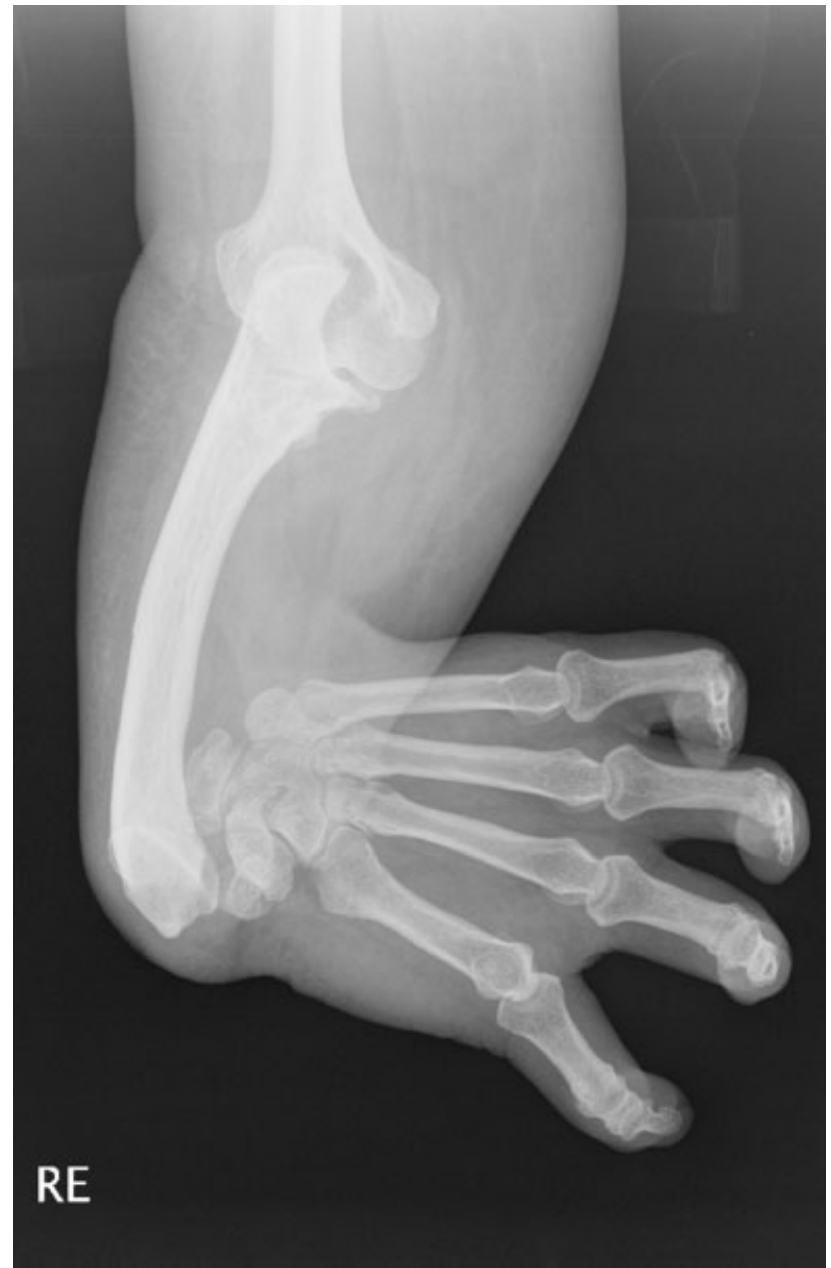

Fig. 6 Radial ray syndrome. Radiographs showing bilateral absence of the radius and the thumb (oligodactyly).

dromes may also cause acro-osteolysis or pointing of the distal phalanges (- Fig. S4).

The most frequent abnormality regarding the morphology of the individual bones consist of cone-shaped epiphyses of the phalanges, either occurring as an isolated finding (-Fig. 14) or as part of an inheritable disorder (-Fig. 7).

A delta phalanx or longitudinal epiphyseal bracket is caused by $\mathrm{C}$-shaped secondary bone growth in an aberrant epiphysis extending along one side of the diaphysis. This leads to asymmetric longitudinal growth of the diaphysis, resulting in a rhomboid or triangular shape of the phalanges. ${ }^{3,15}$ It most commonly affects the proximal phalanx of the thumb (-Fig. 15) or the middle phalanx of the fifth finger. ${ }^{16,17}$

Angel-shaped phalanges, resembling little angels of a Christmas tree, are unusual and may be seen in angel-shaped phalangeal-epiphyseal dysplasia, a rare autosomal dominant inherited disorder characterized by delayed bone age, abnormal dentition, hyperextensibility of the interphalangeal joints, and premature coxartrosis. ${ }^{3}$

Pseudo-epiphyses are "epiphyses" located at an abnormal site such as the base of the second metacarpal. They may be seen as a normal variant, particularly at the base of the second and fifth finger ( - Fig. S5), or occur in cleidocranial dysplasia, brachydactyly C, chondro-ectodermal dysplasia, Fanconi's 


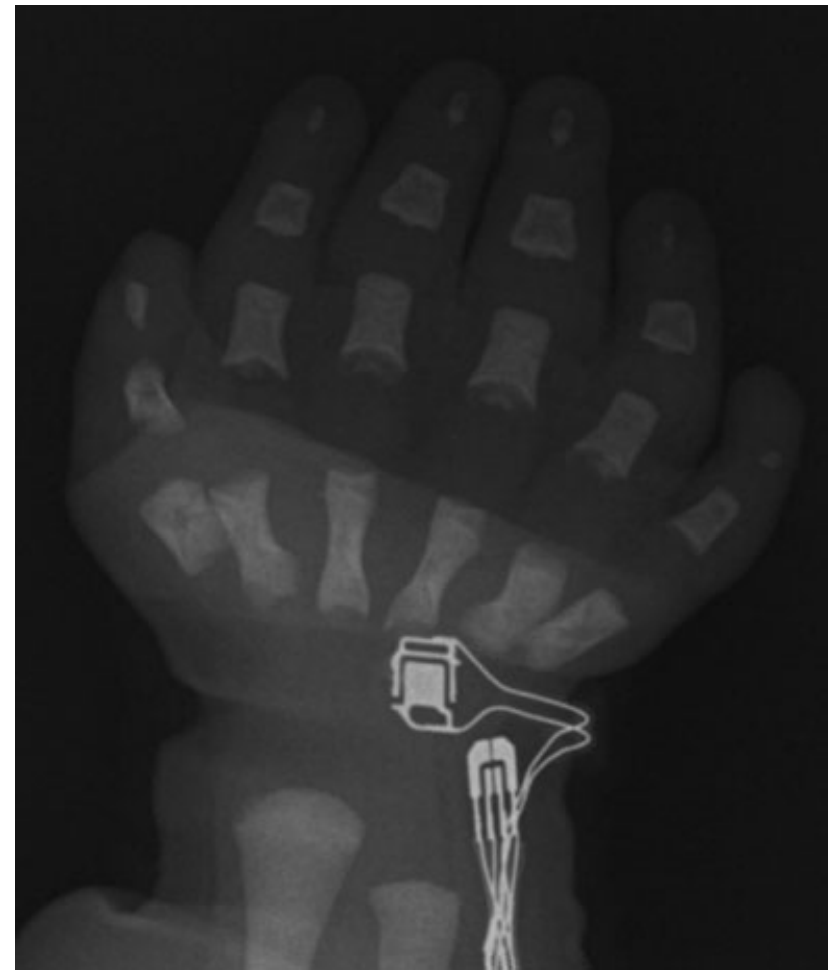

Fig. 7 Radiograph of the right hand in a patient with Ellis-van Creveld syndrome. Note postaxial polydactyly, shortening of the tubular bones, cone-shaped epiphyses, and hypoplasia of the terminal phalanges (reproduced from De Jongh et $\mathrm{al}^{6}$ with permission).
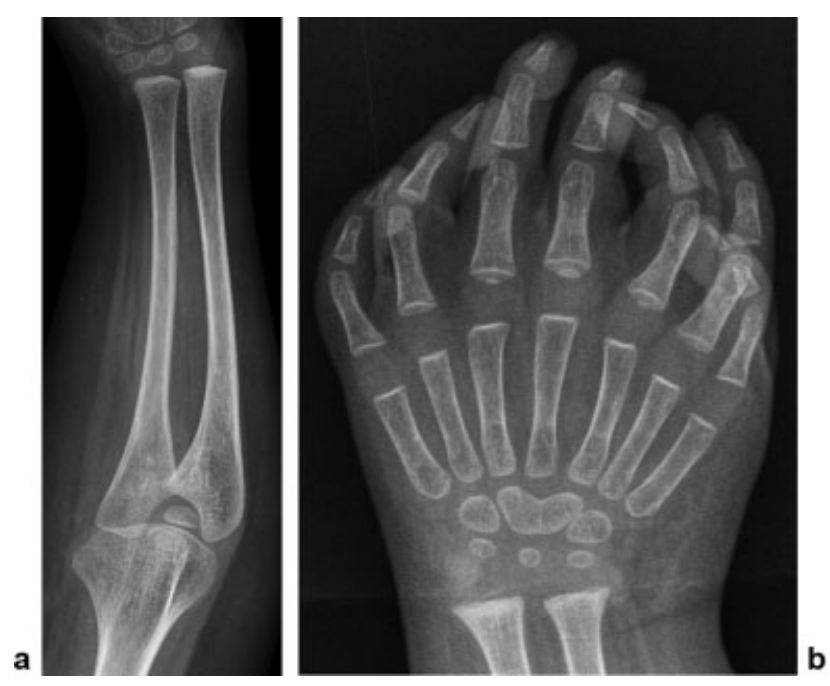

Fig. 8 Ulnar dimelia. Radiographs of (a) the right forearm and (b) the hand show duplication of the ulna and ulnar carpal bones and symmetric postaxial polydactyly. There is absence of the radius, radial carpal bones, and radial-sided fingers. Note segmentation failure of the central carpal bone of the distal carpal row.

anemia, Kniest disease, Larsen's syndrome, otopalatodigital syndrome, and chromosomal abnormalities. ${ }^{3}$

Metaphyseal changes consist of splaying, cupping, widening, and irregularity (-Fig. 16).

Other morphological changes may involve the carpal bones and consist of smallness, scalloping, and irregularity (-Fig. S6).

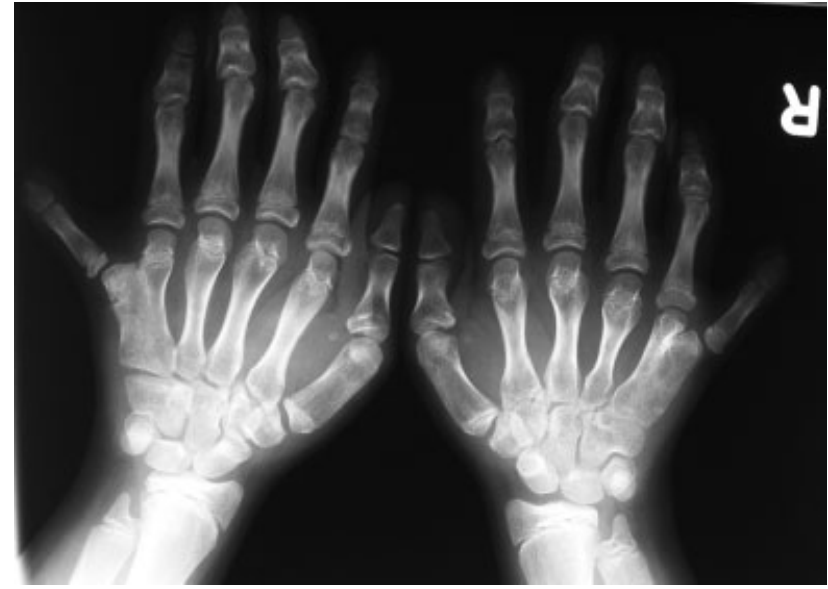

Fig. 9 Bony syndactyly in another patient with Ellis-van Creveld syndrome. Radiographs of both hands showing postaxial polydactyly with osseous fusion between metacarpal 5 and the metacarpal of the extra digit.

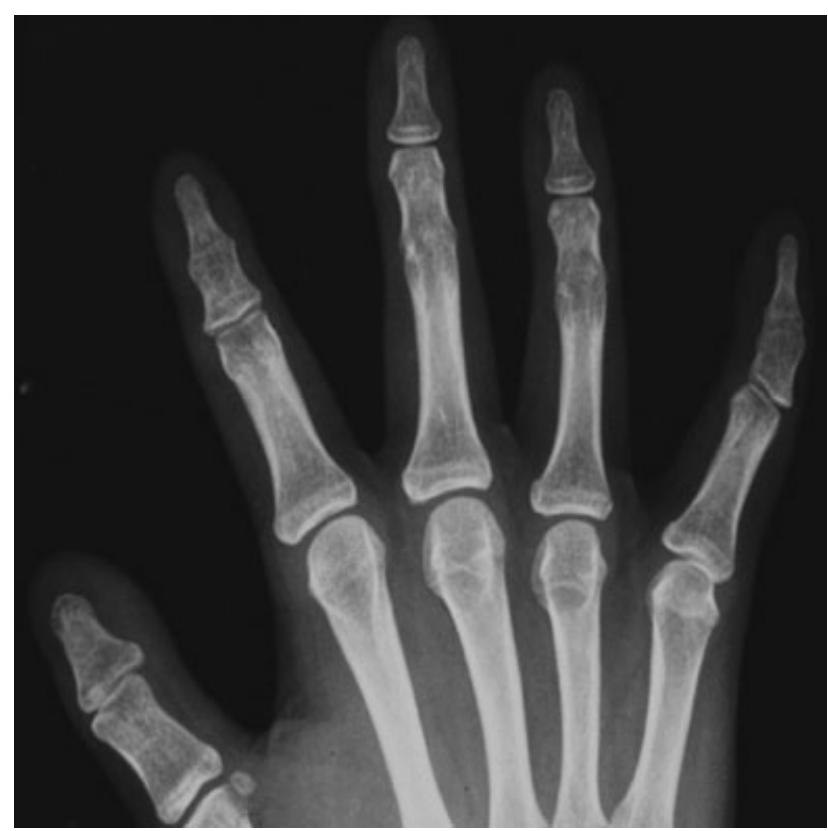

Fig. 10 Variable symphalangism in Pfeiffer's syndrome. Note fusion of the distal interphalangeal joints at the second and fifth finger and fusion of the proximal interphalangeal joints at the third and fourth finger.

At the level of the distal radius and ulna, one has to look for an abnormal carpal angle that should range between 130 and 137 degrees. A decreased carpal angle is associated with Turner's syndrome, Leri-Weill dyschondrosteosis, dysostosis multiplex congenita, ${ }^{13}$ and Madelung's deformity or pseudoMadelung's due to hereditary multiple exostosis (HME) syndrome. The carpal angle may also be enlarged in Down syndrome and a number of dysplasias.

\section{Additional Criteria}

\section{Abnormal Bone Age}

The bone age is delayed in many congenital diseases or dysplasias, although this is a nonspecific finding that may present in many other disorders. 


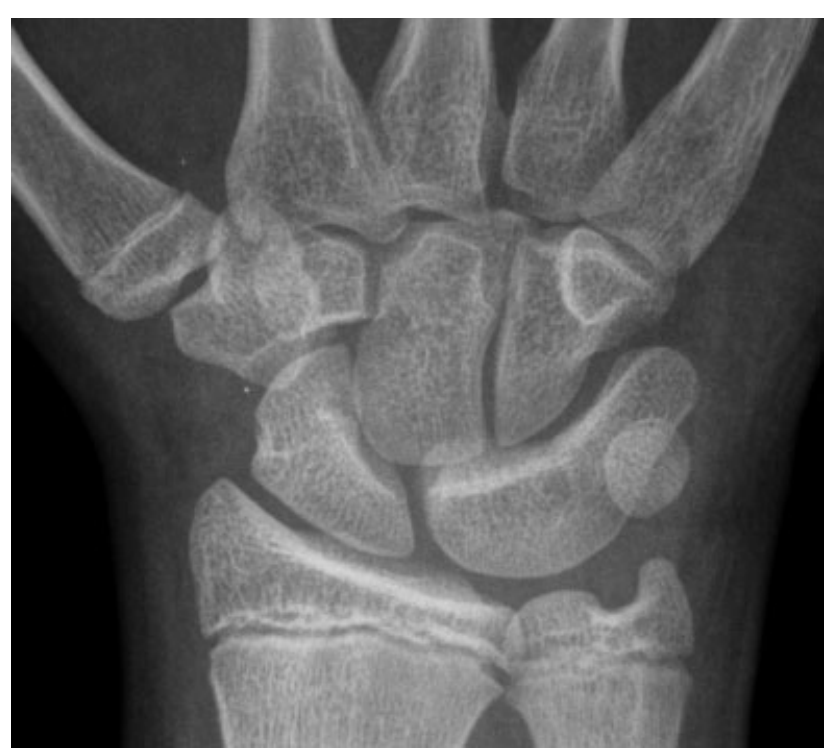

Fig. 11 Carpal coalition. Note failure of segmentation between the lunate and the triquetrum.

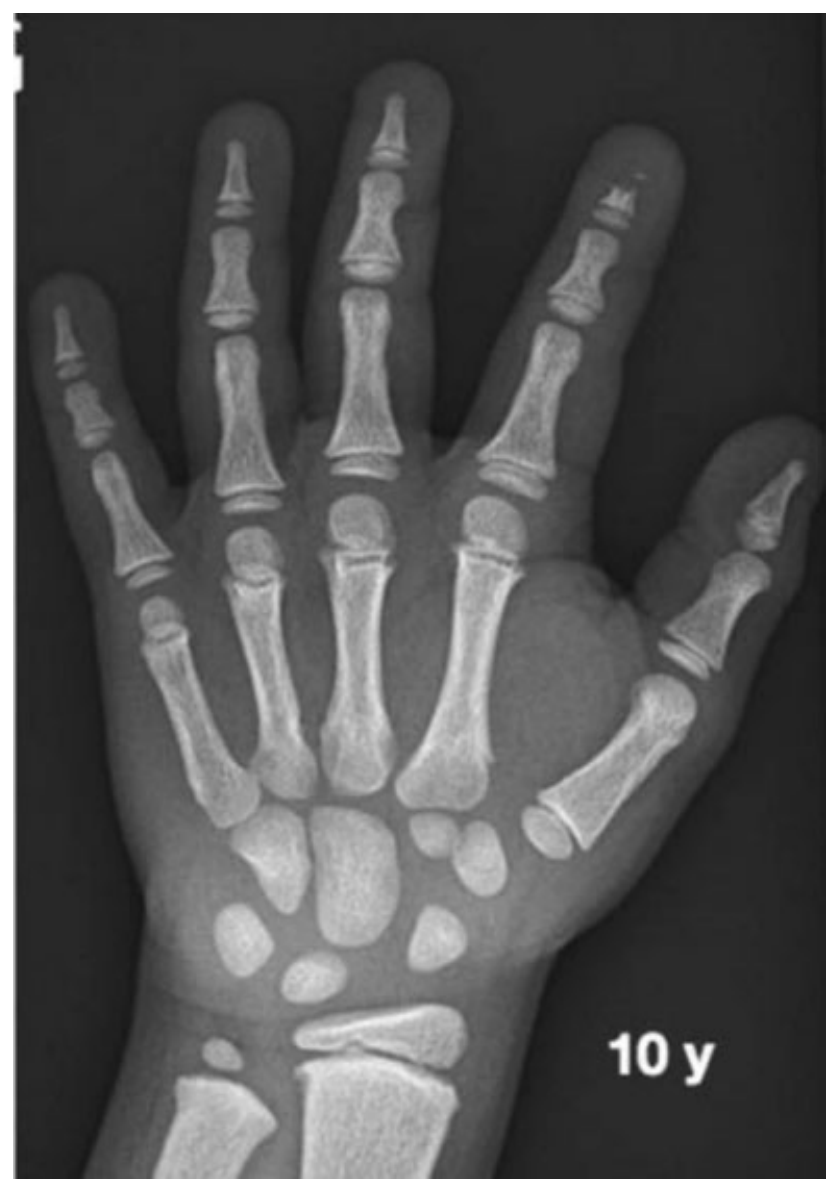

Fig. 12 Pyknodysostosis. Radiograph of the left hand showing osteolysis of the distal phalanx of the second finger and subtle irregularity of the tuft of the distal phalanges of the thumb, third, and fourth finger.

\section{Abnormalities in Mineralization, Either Sclerosis or Demineralization}

Ivory epiphyses of the phalanges are usually a normal variant, but they may be part of a variety of malformation syndromes and dysplasias, such as trichorhinophalangeal syndrome, Cock-

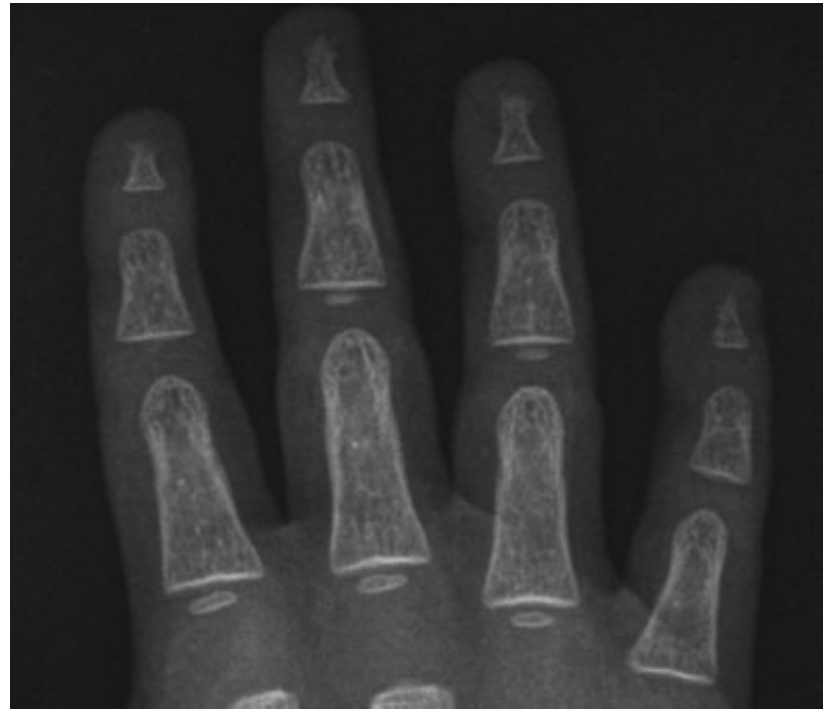

Fig. 13 Progeria. Radiographs of the right hand showing subtle acroosteolysis at the terminal phalanges of the second to fifth finger. Subtle changes are often difficult to distinguish from the normal blunted appearance of the tufts of the distal phalanges in young children.

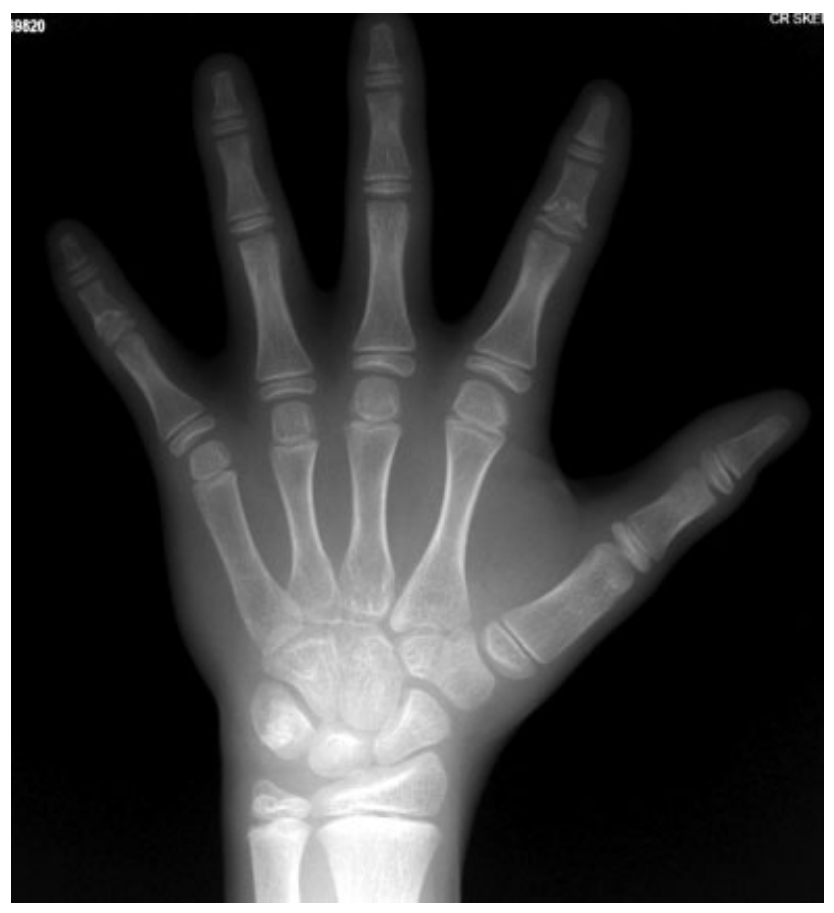

Fig. 14 Cone-shaped epiphyses as incidental findings. Radiograph of the left hand showing cone-shaped epiphyses at the middle phalanx of the second and fifth finger.

ayne's syndrome, and epiphyseal dysplasia., ${ }^{3,18}$ In contrast to normal variants, ivory epiphyses associated with congenital disorders are usually multiple and occur in combination with other anomalies. ${ }^{18}$ Normal variants typically involve the distal phalanges of the second to fifth finger or the middle phalanx of the fifth finger. They disappear after closure of the growth plate. $^{18}$ Sclerosis, fragmentation, and irregularity of the epiphyses of the proximal interphalangeal and distal interphalangeal joints can also occur in Thiemann's syndrome, 


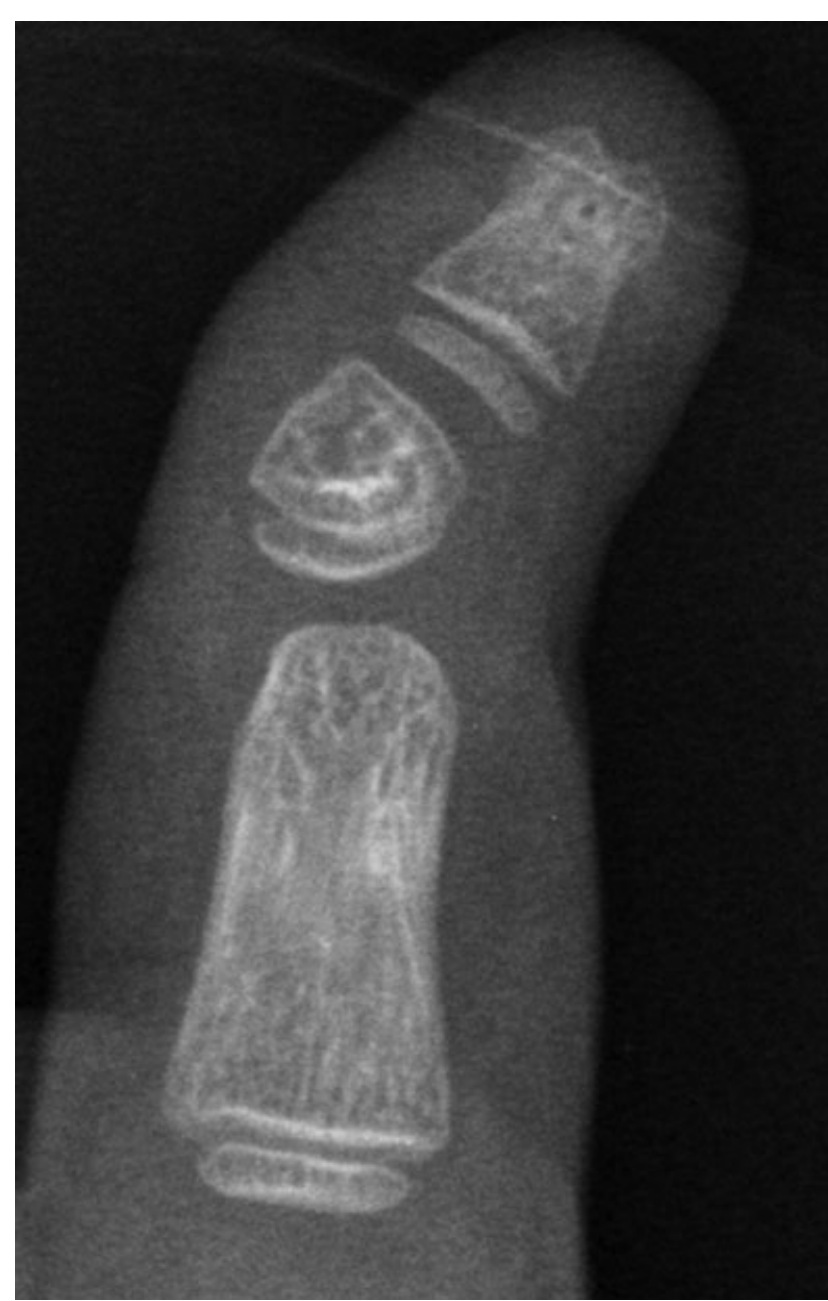

Fig. 15 Delta phalanx. Note a rhomboid shape of the proximal phalanx of the thumb.

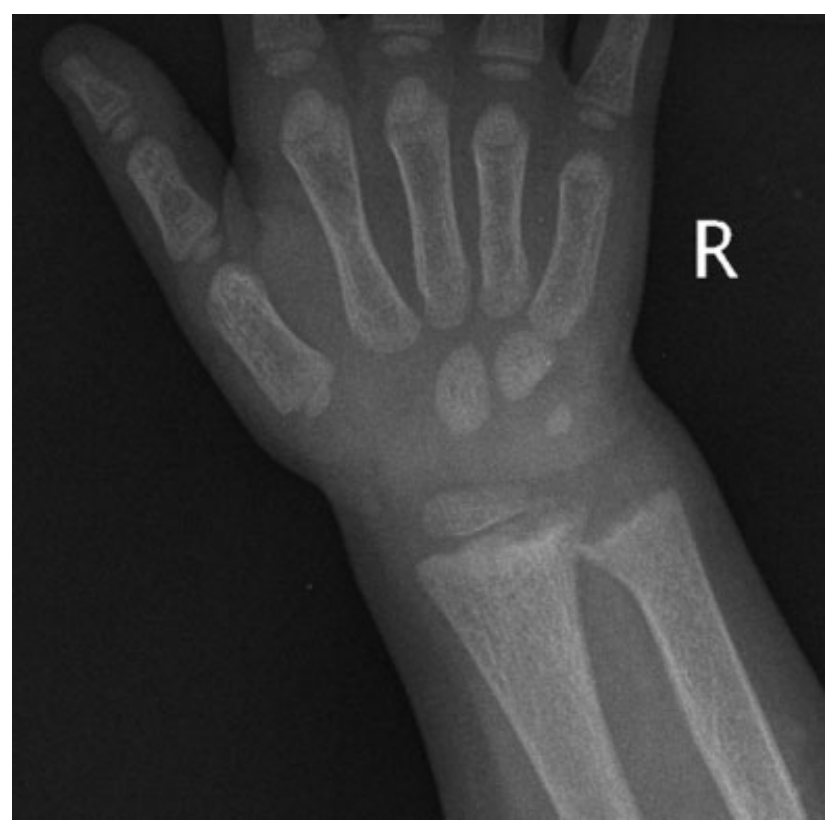

Fig. 16 Metaphyseal changes in hereditary rickets (X-linked hypophosphatemia). Radiograph of the wrist showing osteopenia with coarse trabeculation and widening of the growth plate of the radius, irregularity of the growth plate at the metaphyseal side, and cupping of the metaphysis of the distal ulna. an autosomal dominant inherited familial osteoarthropathy with osteonecrosis. $^{19,20}$

Sclerosing bone dysplasias, affecting the intramembranous bone formation and remodeling, are responsible for cortical thickening. ${ }^{21}$ The cortical thickening may be caused either by a disturbance in the periosteal bone formation and apposition or due to a defective endosteal resorption. According to the involved mechanism, the diaphysis may be broadened (increased periosteal apposition), the medullary cavity may be narrowed (defective endosteal resorption), or a combination of these mechanisms. Van Buchem's disease has a predominant defective endosteal resorption (-Fig. 17), whereas in CamuratiEngelmann disease, disturbance of the periosteal apposition is the main finding.

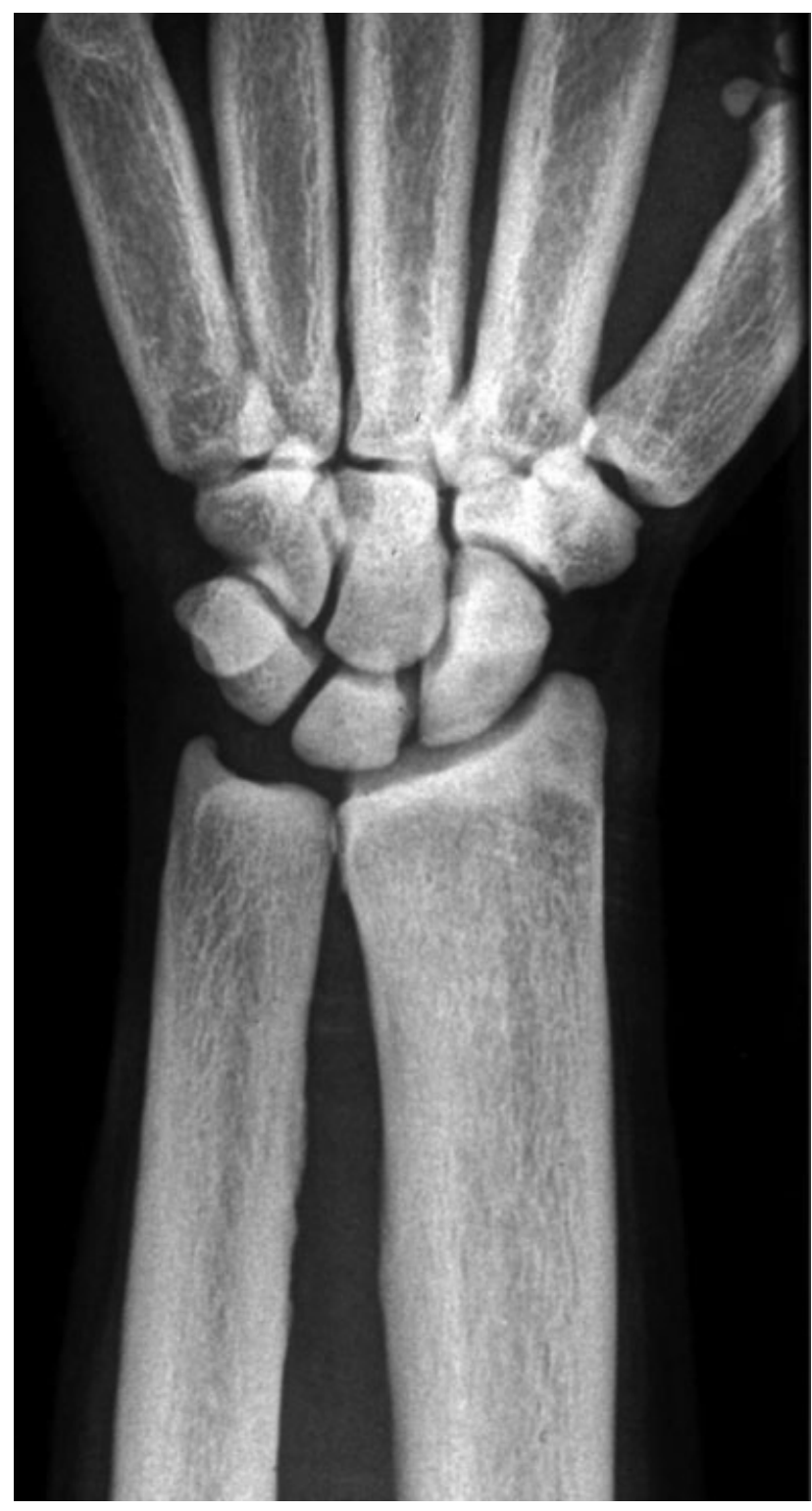

Fig. 17 Van Buchem's disease. Radiograph of left hand showing overall increased density of the radius, ulna, metacarpals, and carpal bones. Note defective modeling of the tubular bones, cortical hyperostosis, and narrowing of the medullary cavity. 


\section{Joint Configuration}

Flexion deformities of the joints of the hands may be seen in dysostosis multiplex congenita (-Fig. 2).

Positional abnormalities of the fingers (and toes) can be due to an abnormal form of a phalanx or mechanical intrauterine stress. Overlapping fingers are seen in some chromosomal abnormalities (trisomy18).

Clinodactyly consists of a radial deviation of a finger, typically the fifth finger. It usually results from an abnormal shape and shortening of the middle phalanx ( - Fig. S7). It can be isolated or part of a variety of malformation syndromes. ${ }^{3}$

Camptodactyly consists of a fixed flexion deformity of the proximal interphalangeal joints, most commonly involving the fifth finger. Most cases are sporadic, but a genetic etiology with autosomal dominant inheritance may occur. $^{3}$ Radiographs can confirm the flexion deformity on the lateral view but fail to demonstrate underlying soft tissues abnormalities. Ultrasound and magnetic resonance imaging (MRI) may demonstrate aberrant lumbrical insertion and decreased lumbrical size in the case of camptodactyly. ${ }^{22}$

Kirner's deformity is a combination of camptodactyly and clinodactyly of the fifth distal phalanx. ${ }^{8}$

A hitchhiker thumb is a characteristic finding seen in diastrophic dysplasia but may be seen in Rubinstein-Taybi syndrome (-Fig. 18) and Pfeiffer's syndrome as well.

\section{Calcifications}

Stippled soft tissue calcifications are seen in chondrodysplasia punctata, Zellweger's syndrome, and Smith-LemliOpitz syndrome.

Phleboliths are characteristic for soft tissue hemangiomas and may indicate Maffucci's syndrome if combined with enchondromas. Scleroderma-like soft tissue calcifications may be encountered in Albright's osteodystrophy (-Fig. 4b).

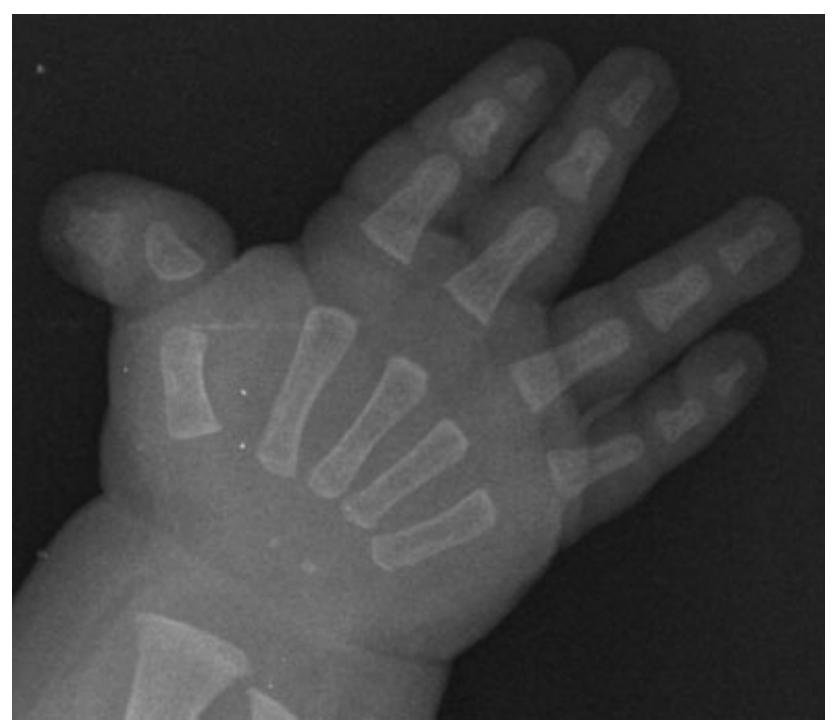

Fig. 18 Radiograph of the right hand showing a hitchhiker thumb in a patient with Rubinstein-Taybi syndrome. Note also a trapezoid shape of the proximal phalanx of the thumb and a broad distal phalanx.

\section{Associated Bone and Soft Tissue Tumors}

Cartilaginous exostoses are the hallmark of HME syndrome. Ollier's disease is characterized by multiple enchondromas, whereas in Maffucci's syndrome, enchondromas are associated with soft tissue hemangiomas.

\section{Soft Tissue Findings}

Macrodactyly refers to enlargement of one or more digits and may be associated with macrodystrophia lipomatosa (-Fig. S8), Proteus syndrome, neurofibromatosis, hemangiomatous, or lymphangiomatous tumors of the hands or feet.

In summary, in addition to correct evaluation of other skeletal abnormalities, meticulous analysis of radiologic features of the hand and wrist may provide important clues to correct identification of congenital diseases of the skeleton. To achieve a more specific diagnosis, we refer to textbooks, ${ }^{15}$ lists of gamuts, ${ }^{5}$ review articles, ${ }^{23,24}$ and Internet databanks on the subject that can be of particular help for the radiologist. ${ }^{25}$ The radiologist should be aware of clinical presentation and family history data. ${ }^{14}$ Ideally, the radiologic findings should be discussed with the referring pediatrician or geneticist. ${ }^{26}$

Whereas the hand is often involved in many congenital diseases, the absence of hand abnormalities may be diagnostic as well. A typical example is spondyloepiphyseal dysplasia, in which the hand bones are typically normal, despite striking dysplastic changes that are present in the spine and epiphyses of the large bones.

\section{Examples of Congenital and Developmental Diseases Involving Hand and Wrist}

\section{Achondroplasia}

Achondroplasia is the most frequent skeletal dysplasia in the general population. It has an autosomal dominant inheritance and is caused by a disturbance in endochondral ossification due to FGPR3 mutation.

Clinically, patients have a short stature with predominant shortening of the proximal segments (humeri and femora), also known as a rhizomelic form of dwarfism.

In addition to bone shortening, radiologic features include disproportionately enlarged head, spinal stenosis, narrowing of the foramen magnum and thoracolumbar kyphosis, and lumbosacral lordosis.

Radiographs of the hand may show a trident hand, ${ }^{13}$ consisting of divergence of the middle three fingers at the level of the proximal interphalangeal joints, due to an inability to oppose the middle and the ring finger ( - Fig. 1 ). The middle three fingers are of equal length, ${ }^{13}$ often more obvious on clinical inspection than on radiographs. The phalanges are shortened and may have a bullet-shaped appearance (-Fig. 1). ${ }^{27}$

\section{Thanatophoric Dysplasia}

Thanatophoric dysplasia is the most lethal neonatal skeletal dysplasia. ${ }^{28}$ The term "thanatophoric" is derived from the Greek word thanatophorus, meaning "death bearing." Death occurs very soon after birth because of respiratory distress due to a small thoracic cage. As in achondroplasia, there is 


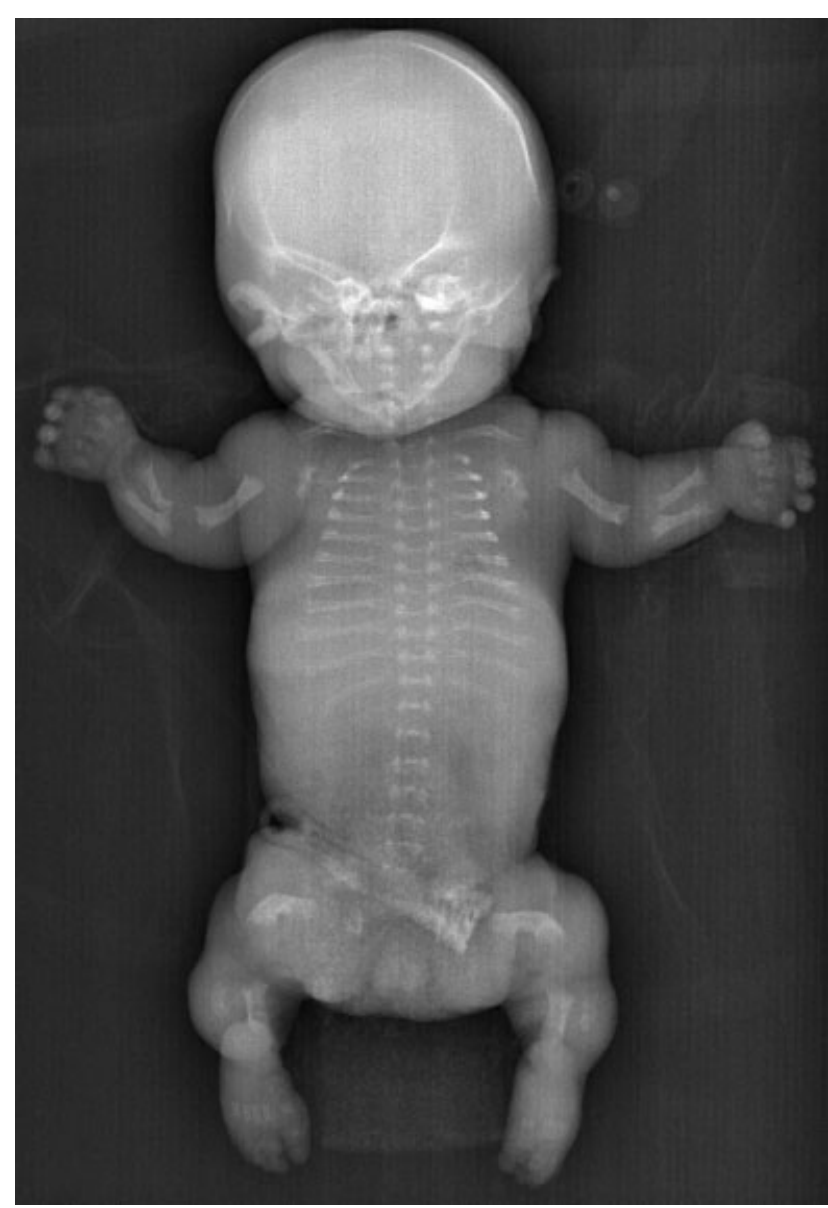

Fig. 19 Postmortem babygram in a patient with thanatophoric dysplasia. Note a long and narrow trunk with very short ribs and a disproportionate large head. Platyspondyly and marked shortening of the long bones (including the bones of the hand). The femora are curved and have a "French telephone receiver" appearance.

failure in the endochondral ossification due to a new autosomal dominant FGPR3 mutation. Radiologically, it is similar to achondroplasia, but the shortening of the limbs is much more pronounced with bowing of the long bones, having the shape of a "French telephone receiver." ${ }^{28}$ There is severe platyspondyly. The hands and feet show marked shortening, broadening, and deformity of the tubular bones (-Fig. 19).

\section{Diastrophic Dysplasia}

Diastrophic dysplasia, also called atypical achondroplasia with clubbed hands and feet, is a dysplasia due to disturbance of the endochondral bone formation. It is inherited in an autosomal recessive way because of a mutation in the DTDST (diastrophic dysplasia sulfate transporter) gene. The term "diastrophic" is derived from the Greek word diastrophism that refers to the geologic process of bending of the earth's crust by which mountains, continents, and ocean basins are formed. ${ }^{25}$

Radiologically, the tubular bones are short, thick, and clubbed with delay in ossification and fragmentation of the epiphyses, multiple joint dislocations, and progressive scoliosis and kyphosis. Radiographs of the hand show a typical hitchhiker's thumb with shortening and deformity of the first metacarpal with a proximally located thumb (- Fig. S9). 5, 15,25

\section{Chondroectodermal Dysplasia}

Chondroectodermal dysplasia, also known as Ellis-van Creveld syndrome, is a skeletal ciliopathy, with an autosomal recessive inheritance due to a mutation in the EVS or EVC2 gene. ${ }^{29}$

Radiologically, the ribs are short, the acetabuli have a trident shape, and the limbs are shortened with bulbous ends. Particularly the proximal ulnae and distal radii are bulbous, whereas the distal ulnae and proximal radii are narrow, resulting in a "chicken drumstick" appearance. ${ }^{29}$ The spine and skull are normal. ${ }^{6,29}$ Radiographs of the hands show brachydactyly, cone-shaped epiphyses of the (middle) phalanges 2 through 5, and postaxial and/or mesoaxial polydactyly of the hands. ${ }^{6}$ Hypoplasia of the distal phalanges and capitate-hamate fusion are other characteristic findings ${ }^{29,30}$ (-Figs. 7 and 9).

\section{Albright Hereditary Osteodystrophy}

Albright hereditary osteodystrophy consists either of pseudohypoparathyroidism or pseudo- pseudohypoparathyroidism. Radiologically, soft tissue calcifications and brachydactyly type $\mathrm{E}$ of the hands (and feet) are seen, with a positive metacarpal sign (-Fig. 4).

\section{Pyknodysostosis}

Pyknodysostosis is a sclerosing bone dysplasia due to defective endochondral bone formation affecting primary spongiosa. Its inheritance is autosomal recessive due to mutations in the CSTK gene encoding cathepsin K. Clinically, patients have a small stature. Radiologically, there is sclerosis of the tubular bones with preservation of the corticomedullary differentiation. Bone fragility is increased, and there is decreased pneumatization of the paranasal sinuses and delayed suture closure. Acro-osteolysis or pencil-like pointing of the distal phalanges of the hand is a characteristic finding (-Fig. 12). ${ }^{31}$

\section{Osteopetrosis}

Osteopetrosis is a sclerosing bone dysplasia due to defective endochondral bone formation affecting the primary spongiosa. The inheritance and phenotype is heterogeneous. ${ }^{31}$

Two basic adult phenotypes of osteopetrosis are distinguished. In type I, uniform sclerosis is found in the skull, spine, and long bones, whereas endobones ("bone-in-bone") and rugger-jersey spine are present in type II. ${ }^{21,32}$ The bones of the hands may be involved as well.

\section{Osteopoikilosis}

Osteopoikilosis is a disturbance of endochondral ossification that consists of an error in resorption or remodeling of secondary spongiosa, resulting in focal multiple bone islands at the end of tubular bones and at the carpal and tarsal bones. These sclerotic foci have typical peripheral thorny radiations, blending with the trabeculae of the adjacent secondary spongiosa (-Fig. 20).

\section{Melorheostosis}

Melorheostosis is a mixed sclerosing bone dysplasia due to a disturbance of intramembranous and, to a lesser degree, endochondral ossification. ${ }^{21}$ It is not inherited and believed 


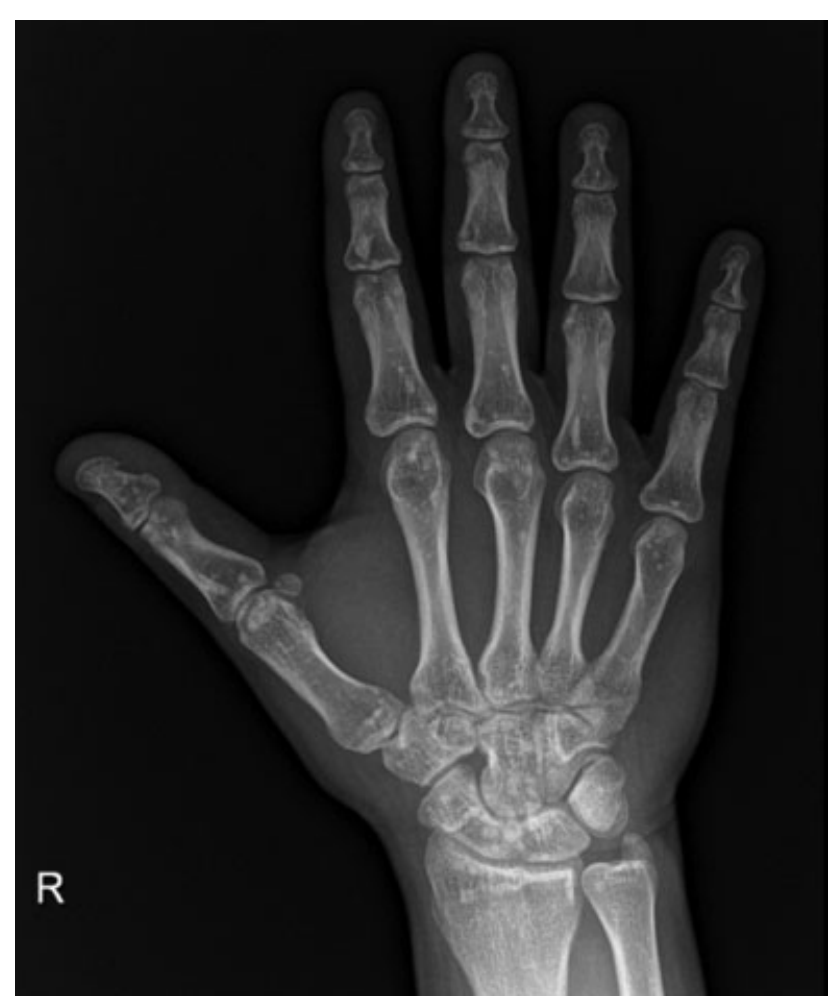

Fig. 20 Osteopoikilosis. Radiograph of the right hand showing multiple dense bone islands at the carpus and at the end of the tubular bones.

to occur as a result of a defect in the early embryological stage, where cartilage-forming cells migrate from the sclerotomes to the limb buds. ${ }^{21}$ Radiologically, there is typical unilateral involvement (hemimelic) "flowing" hyperostosis of the cortex of the bones included resembling wax dripping down one side of a candle. Soft tissue involvement with a "myositis ossificans" and an "osteoma-like" pattern may occur as well. There are several reports on involvement of the bones of the hand. ${ }^{21,33-36}$

\section{Progeria}

Progeria is a rare autosomal dominant disorder due to a new mutation characterized by accelerated aging at a very young age. The word "progeria" comes from the Greek words pro meaning "before" or "premature," and gēras meaning "old age." Although the term progeria refers to all diseases characterized by premature aging symptoms, it is often specifically used to designate Hutchinson-Gilford progeria syndrome. ${ }^{7}$ Radiographs of the hand may show sclerodermalike lesions including calcifications and acro-osteolysis (-Fig. 13). . $^{37-39}$

\section{Hereditary Rickets}

Hereditary rickets are a group of disorders with a heterogeneous inheritance. Radiologically, they do not differ from secondary rickets, showing demineralization with coarsened trabeculae, bowing of the long bones, poorly ossified epiphyses, widening of the growth plates, metaphyseal cupping, and fraying and flaring (-Fig. 16). ${ }^{15}$

\section{Hereditary Multiple Exostosis Syndrome}

HME syndrome is an autosomal dominant inherited bone disorder with an incidence of 1 in $50,000 .{ }^{40}$ It is a genetically heterogeneous disease, and most cases are linked to loss-offunction mutations in EXT1 or EXT2. ${ }^{41-45}$

There is defective endochondral bone formation, resulting in multiple exostoses or osteochondromas at the juxtaepiphyseal regions of bones.

In addition, there is also a defective (re)modeling at the metaphyses of the long bones, leading to mild dwarfing, metaphyseal widening, with the formation of trumpetshaped bones and wrist deformities ("bayonet hand"), owing to shortening of the ulna. Common osseous deformities include a pseudo-Madelung's deformity of the wrist, with ulnar shortening and (secondary) radial bowing (-Fig. S10). ${ }^{13}$ Complications may occur due to local entrapment of vessel, tendon, nerve, bursitis de novo, and sarcomatous transformation. ${ }^{45}$

\section{Metachondromatosis}

Metachondromatosis (MC) is a rare disorder characterized by the presence of both multiple enchondromas and osteochondroma-like lesions, most commonly occurring at the hands or feet. MC has an autosomal dominant mode of inheritance and is caused by loss-of-function mutations including deletions, nonsense mutations, and splice sites mutations of the PTPN11 gene (12q24). ${ }^{45}$ Compared with HME, no malignant transformation has been described. ${ }^{45}$

\section{Ollier's Disease}

Enchondromatosis, also known as Ollier's disease, consists of multiple enchondromas, often affecting the hand and wrist. The estimated prevalence of Ollier's disease is 1 in 100,000. Ollier's disease is not inherited and has a sporadic occurrence.

There is usually an asymmetric distribution of the lesion, affecting one side of the body. Affected bones are often shortened and curved. Forearm deformities are frequently encountered similar to those observed in HME. ${ }^{45}$ Radiographs show multiple enchondromas (-Fig. S11) ${ }^{13}$ and widening of the metaphysis. There is a potential risk for a malignant change to chondrosarcoma. ${ }^{45}$

\section{Maffucci's Disease}

Multiple enchondromas associated with soft tissue hemangiomas is known as Maffucci's syndrome. Similar to Ollier's disease, Maffucci's disease is not inherited and has a sporadic occurrence. The hand and wrist is often involved. In addition to multiple enchondromas, radiographs show typical phleboliths that are characteristic for soft tissue hemangiomas. ${ }^{46}$

\section{Pachydermoperiostosis}

Pachydermoperiostosis is a rare disorder with an autosomal recessive or dominant inheritance. Mutations in the HPGD gene were found in those with the autosomal recessive form. ${ }^{23}$

Clinically, there is thickening of the skin of the face (pachyderma), excessive sweating (hyperhidrosis), and clubbing of the fingers. The disease starts at childhood age or at puberty, and it progresses slowly for $\sim 10$ years. ${ }^{23}$ 

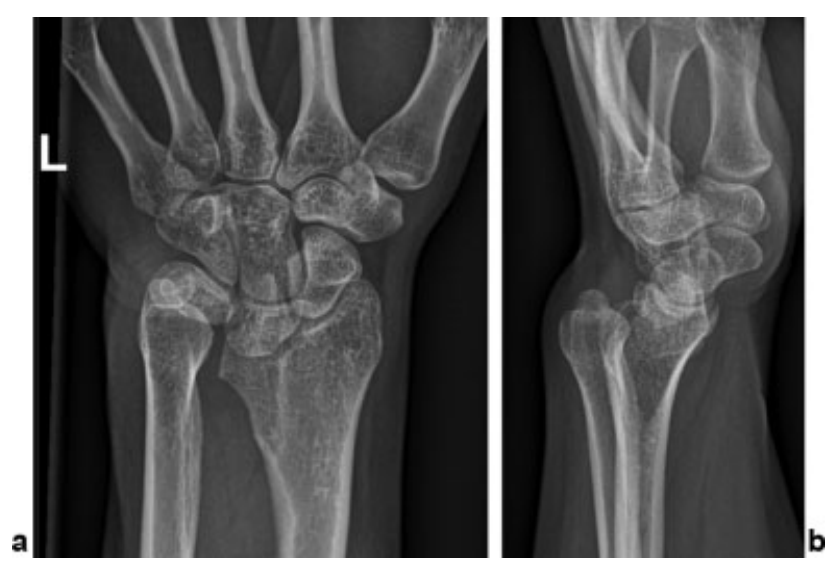

Fig. 21 Leri-Weill dyschondrosteosis. (a) Posteroanterior and (b) lateral view of the wrist showing Madelung's deformity of the wrist and dorsal subluxation of the ulna to the carpus.

Radiographs show irregular periosteal ossification affecting predominantly the distal ends of long bones. ${ }^{47,48}$ The bones of the hand may show periosteal reaction and acro-osteolysis. ${ }^{49,50}$

Ultrasound may show increased echogenicity and increased vascularity adjacent to the long bones, presumably reflecting edema and inflammatory tissue. ${ }^{50}$ On MRI, periosteal reaction is hyperintense on short tau inversion recovery images and enhances after administration of gadolinium contrast. ${ }^{50}$

\section{Leri-Weill Dyschondrosteosis}

Dyschondrosteosis is a rare genetic skeletal dysplasia marked by disproportionate short stature. Its inheritance is pseudoautosomal dominant due to mutations of the SHOX gene. ${ }^{51}$ Radiographs of the wrist show a characteristic Madelung's deformity of the wrist (-Fig. 21). ${ }^{52}$

On MRI, congenital Madelung's deformity is characterized by a hypertrophic Vickers ligament extending from a bony gutter at the ulnar side of the distal radius to the lunate and/or triquetrum ${ }^{8,53}$ that are not present in acquired Madelung-type deformities. ${ }^{52}$

Because there may be associated elbow dislocation and cubitus valgus, it may be important to visualize the entire forearm, especially in case of restricted elbow mobility. ${ }^{15}$

\section{Multicentric Carpal-Tarsal Osteolysis}

Multicentric carpal-tarsal osteolysis is a rare autosomal dominant condition for which the gene defect still remains unknown.

Clinically, there are two main subtypes: with or without nephropathy. Symptoms including joint pain, swelling, and tenderness usually starts in childhood and may lead to progressive limb deformity in the third decade.

In early-stage disease, there is osteopenia with loss of the bony contour, followed by progressive osteolysis of the carpal and tarsal bones, ultimately resulting in collapse, fragmentation, and sclerotic carpal and tarsal bones. Partial resorption of adjacent tubular bones may lead to tapering of the proximal ends of the metacarpals and metatarsals with a characteristic "sucked candy" appearance. The other joints such as elbow and shoulder are less commonly involved. ${ }^{54,55}$

\section{Conclusion}

The hand may serve as an important window to the diagnosis of congenital disorders of the skeleton. We recommend scrutinizing the radiologic semiology systematically as the first step in successful characterization. In addition, every case should be discussed with the referring pediatrician and/or clinical geneticist to obtain a more specific diagnosis. Finally, the radiologist should be familiar with the main features of most common inherited bone diseases.

Conflict of Interest

None declared.

\section{References}

1 Vanhoenacker FM, Van Hul W, Gielen J, De Schepper AM. Congenital skeletal abnormalities: an introduction to the radiological semiology. Eur J Radiol 2001;40(03):168-183

2 Bell J. On brachydactyly and symphalangism. In: Penrose L, ed. The Treasury of Human Inheritance. Cambridge, UK: Cambridge University Press; 1951

3 Castriota Sanderbeg A, Dallapiccola B. Congenital defects, malformation syndromes and skeletal dysplasias. In: Guglielmi G, van Kuijk C, Genant H.K., eds. Fundamentals of Hand and Wrist Imaging. Berlin, Germany: Springer; 2001:155-202

4 Archibald RM, Finby N, De Vito F. Endocrine significance of short metacarpals. J Clin Endocrinol Metab 1959;19:1312-1322

5 Kozlowski K, Beighton P, eds. Gamut Index of Skeletal Dysplasias. An Aid to Radiodiagnosis 3rd ed. London, UK: Springer; 2001

6 de Jongh K, Vanhoenacker FM, Van de Perre S, Mertens G, De Schepper AM. Chondroectodermal dysplasia. JBR-BTR 2006;89 (03):124-125. Accessed April 18, 2020 at: http://www.ncbi.nlm. nih.gov/pubmed/16883754

7 Progeria. Accessed April 19, 2020 at: https://en.wikipedia.org/wiki/Progeria\#cite_note-10

8 Aucourt J, Budzik JF, Manouvrier-Hanu S, Mézel A, Cotten A, Boutry N. Congenital malformations of the hand and forearm in children: what radiologists should know. Semin Musculoskelet Radiol 2012;16(02):146-158

9 Yang SS, Jackson L, Green DW, Weiland AJ. A rare variant of mirror hand: a case report. J Hand Surg Am 1996;21(06):1048-1051

10 Foucras L, Grolleau JL, Chavoin JP. Poland's syndrome and hand's malformations: about a clinic series of 37 patients. [in French]. Ann Chir Plast Esthet 2005;50(02):138-145

11 Friedman T, Reed M, Elliott AM. The carpal bones in Poland syndrome. Skeletal Radiol 2009;38(06):585-591

12 Carlson DH. Coalition of the carpal bones. Skeletal Radiol 1981;7 (02):125-127

13 Ngo AV, Thapa M, Otjen J, Camps SE. Skeletal dysplasias: radiologic approach with common and notable entities. Semin Musculoskelet Radiol 2018;22(01):66-80

14 Alayna Y, Lachman RS. A review of the principles of radiological assessment of skeletal dysplasias. J Clin Res Pediatr Endocrinol 2011;3(04):163-178

15 Lachman RS. Taybi and Lachman's Radiology of Syndromes, Metabolic Disorders and Skeletal Dysplasias. 5th ed. Philadelphia, PA: Mosby-Elsevier; 2007

16 Choo AD, Mubarak SJ. Longitudinal epiphyseal bracket. J Child Orthop 2013;7(06):449-454

17 Delta Phalanx | Hand Surgery Source. Accessed May 8, 2020 at: https://www.handsurgeryresource.com/deltaphalanx

18 Cotten A. Pseudo-lesions phalangiennes. In: Cotten A, Vande Berg $B$, eds. 18èmes Mises au Point en Imagerie Osteo-Articulaire. Course syllabus. Bruxelles, Belgium: Enseignement inter-universitaire de radiologie osteo-articulaire; 2018:175-178 
19 van der Laan JG, Thijn CJP. Ivory and dense epiphyses of the hand: Thiemann disease in three sisters. Skeletal Radiol 1986;15(02): 117-122

20 Mangat P, Jawad ASM. Case number 32: Thiemann's disease. Ann Rheum Dis 2005;64(01):11-12

21 Vanhoenacker FM, De Beuckeleer LH, Van Hul W, et al. Sclerosing bone dysplasias: genetic and radioclinical features. Eur Radiol 2000;10(09):1423-1433

22 Favril A, Vanhoenacker F, Goubau Y, Jager T. Camptodactyly resulting from anatomical variation of lumbrical muscles: imaging findings. Skeletal Radiol 2019;48(12):2009-2014

23 Offiah AC, Hall CM. Radiological diagnosis of the constitutional disorders of bone. As easy as A, B, C? Pediatr Radiol 2003;33(03):153-161

24 Panda A, Gamanagatti S, Jana M, Gupta AK. Skeletal dysplasias: a radiographic approach and review of common non-lethal skeletal dysplasias. World J Radiol 2014;6(10):808-825

25 McKusick-Nathans Institute of Genetic Medicine. Johns Hopkins University School of Medicine under the direction of DAH. Online access of the Mendelian Inheritance in Man (OMIM). Available at: https://www.ncbi.nlm.nih.gov/omim/. Accessed January 11, 2021

26 Mortier GR. The diagnosis of skeletal dysplasias: a multidisciplinary approach. Eur J Radiol 2001;40(03):161-167

27 Aleksieva-Ivkova G, Vanhoenacker FM, Mortier GR, Parizel PM. Une cause congénitale de douleur dans le dos et dans les jambes. Ortho-Rhumato 2017;15(05):38-40

28 Sawai H, Oka K, Ushioda M, et al. National survey of prevalence and prognosis of thanatophoric dysplasia in Japan. Pediatr Int (Roma) 2019;61(08):748-753

29 Handa A, Voss U, Hammarsjö A, Grigelioniene G, Nishimura G. Skeletal ciliopathies: a pattern recognition approach. Jpn J Radiol 2020;38(03):193-206

30 Marcelis S, Mortier G, Vanhoenacker F. Marked hypoplasia of the distal phalanges in Ellis-Van Creveld syndrome. J Belg Soc Radiol 2018;102(01):42

31 Boulet C, Madani H, Lenchik L, et al. Sclerosing bone dysplasias: genetic, clinical and radiology update of hereditary and nonhereditary disorders. Br J Radiol 2016;89(1062):20150349

32 Dierickx J, Mortier G, Vanhoenacker F. Une patiente avec des os denses. Ortho-Rhumato 2019;17(05):34-40

33 van Durme CMPG, Starmans-Kool MJF, Peeters HRM. Dripping candle wax. Neth J Med 2012;70(03):140-143

34 Farr S. Melorheostosis in the pediatric hand. Clin Case Rep 2019;7 (05):1110-1111

35 Kumar S, Jain VK, Prabhakar R. Melorheostosis of upper limb: A report of four rare cases.J Clin Orthop Trauma 2020;11(02):321-323

36 Vyskocil V, Koudela K Jr, Pavelka T, Stajdlova K, Suchy D. Incidentally diagnosed melorheostosis of upper limb: case report. BMC Musculoskelet Disord 2015;16(01):2

37 Ho A, White SJ, Rasmussen JE. Skeletal abnormalities of acrogeria, a progeroid syndrome. Skeletal Radiol 1987;16(06):463-468

38 Jansen T, Romiti R. Progeria infantum (Hutchinson-Gilford syndrome) associated with scleroderma-like lesions and acro-osteol- ysis: a case report and brief review of the literature. Pediatr Dermatol 2000;17(04):282-285

39 Cleveland RH, Gordon LB, Kleinman ME, et al. A prospective study of radiographic manifestations in Hutchinson-Gilford progeria syndrome. Pediatr Radiol 2012;42(09):1089-1098

40 Wuyts W, Van Hul W, De Boulle K, et al. Mutations in the EXT1 and EXT2 genes in hereditary multiple exostoses. Am J Hum Genet 1998;62(02):346-354

41 Cook A, Raskind W, Blanton SH, et al. Genetic heterogeneity in families with hereditary multiple exostoses. Am J Hum Genet 1993;53(01):71-79

$42 \mathrm{Wu}$ YQ Heutink P, de Vries BBA, et al. Assignment of a second locus for multiple exostoses to the pericentromeric region of chromosome 11. Hum Mol Genet 1994;3(01):167-171

43 Wuyts W, Ramlakhan S, Van Hul W, et al. Refinement of the multiple exostoses locus (EXT2) to a 3-cM interval on chromosome 11. Am J Hum Genet 1995;57(02):382-387

44 Pacifici M. Hereditary multiple exostoses: new insights into pathogenesis, clinical complications, and potential treatments. Curr Osteoporos Rep 2017;15(03):142-152

45 D'Arienzo A, Andreani L, Sacchetti F, Colangeli S, Capanna R. Hereditary multiple exostoses: current insights. Orthop Res Rev 2019;11:199-211

46 Maffucci syndrome | Genetic and Rare Diseases Information Center (GARD)-an NCATS Program. Available at: https://rarediseases.info.nih.gov/diseases/6958/maffucci-syndrome. Accessed April 21, 2020

47 Supradeeptha C, Shandilya SM, Vikram Reddy K, Satyaprasad J. Pachydermoperiostosis - a case report of complete form and literature review. J Clin Orthop Trauma 2014;5(01):27-32

48 Yap FY, Skalski MR, Patel DB, et al. Hypertrophic osteoarthropathy: Clinical and imaging features. Radiographics 2017;37(01): 157-195

49 Martinez-Lavin M. Miscellaneous non-inflammatory musculoskeletal conditions. Pachydermoperiostosis. Best Pract Res Clin Rheumatol 2011;25(05):727-734

50 Adams B, Amin T, Leone V, Wood M, Kraft JK. Primary hypertrophic osteoarthropathy: ultrasound and MRI findings. Pediatr Radiol 2016;46(05):727-730

51 Binder G. Short stature due to SHOX deficiency: genotype, phenotype, and therapy. Horm Res Paediatr 2011;75(02):81-89

52 Ali S, Kaplan S, Kaufman T, Fenerty S, Kozin S, Zlotolow DA. Madelung deformity and Madelung-type deformities: a review of the clinical and radiological characteristics. Pediatr Radiol 2015;45(12):1856-1863

53 Kim HK. Madelung deformity with Vickers ligament. Pediatr Radiol 2009;39(11):1251

54 Peeters J, Vanhoenacker FM, Mortier G, Parizel PM. Multicentric carpal-tarsal osteolysis. JBR-BTR 2011;94(04):218

55 McDonald K, Toms AP, Armon K, Johnson K, Marshall TJ. Carpaltarsal osteolysis with elbow involvement. Skeletal Radiol 2007;36 (11):1097-1101 